institution and stabilized with femoral venoarterial extracorporeal membrane oxygenation. The patient was deemed a transplant candidate and taken to the operating room 4 days later for mechanical circulatory support. Intraoperative evaluation noted extensive bilateral myocardial necrosis and friability, including the left apex, septum, and a large portion of the right ventricle. The decision was made for TAH-t placement. On postoperative days 0,1 , and 3 , the patient required reexploration and evacuation of hematoma for bleeding and mediastinal hematoma. She continued to progress to multiorgan failure, coagulopathy, and vasodilatory shock despite multipressor support. Evidence of sepsis, including bilateral pneumonia and lactic acidosis, led to discontinuance of support 9 days after TAH-t implantation.

\section{DISCUSSION}

VSDs are rare, life-threatening complications that occur after MI in $1 \%$ to $2 \%$ of patients. ${ }^{1}$ As many as $90 \%$ of patients would die without intervention; however, mortality with emergency surgical or percutaneous repair is still greater than $50 \%{ }^{1}$ Patients who have cardiogenic shock and biventricular failure develop require mechanical support for stabilization until definitive repair or transplant can be performed. Implantable left ventricular assist devices have been successfully used as a bridge to transplant after postMI VSD. ${ }^{3}$ Securing the inflow cannula to infarcted apical myocardium can be technically difficult, and post-MI ventricular arrhythmias may complicate left ventricular assist device management. Severe valvular insufficiency and post-MI extensive left ventricular myocardial loss with poor function may favor replacement of both ventricles.

The TAH-t is a pneumatic, pulsatile pump that replaces the patient's ventricles and native valves. Implantation of the TAH-t has been shown to improve outcomes in unstable patients in end-stage cardiogenic shock by providing immediate hemodynamic stabilization and end-organ perfusion until cardiac transplant can occur. Survivals to transplant with the TAH-t as great as $79 \%$ have been reported, ${ }^{4}$ comparable to biventricular support survival of $56 \%$ at 6 months. ${ }^{5}$ Use of the TAH-t currently obligates the patient to undergo a transplant, and every effort should be made to preserve the patient's own myocardium. All mechanical support devices possess inherent risk factors, including infection, thromboembolism, and hemorrhage.

We present the first 2 cases of patients with post-MI VSD rupture with end-stage cardiogenic shock to undergo TAH-t placement. TAH-t support is an alternative option to biventricular support devices for critically unstable patients with post-MI VSD and extensive ventricular myocardial loss. Mortality was $50 \%$ in this small series, which underlines the complexity of predicting outcomes in this patient population.

\section{References}

1. Arnaoutakis GJ, Zhao Y, George TJ, Sciortino CM, McCarthy PM, Conte JV. Surgical repair of ventricular septal defect after myocardial infarction: outcomes from the Society of Thoracic Surgeons National Database. Ann Thorac Surg. 2012;94: 436-43; discussion 443-4

2. Conradi L, Treede H, Brickwedel J, Reichenspurner H. Use of biventricular mechanical support in a case of postinfarction ventricular septal rupture as a bridge to surgery. Ann Thorac Surg. 2009;87:e37-9.

3. Faber C, McCarthy PM, Smedira NG, Young JB, Starling RC, Hoercher KJ. Implantable left ventricular assist device for patients with postinfarction ventricular septal defect. J Thorac Cardiovasc Surg. 2002;124:400-1.

4. Copeland JG, Smith RG, Arabia FA, Nolan PE, Sethi GK, Tsau PH, et al. Cardiac replacement with a total artificial heart as a bridge to transplantation. $N$ Engl J Med. 2004;351:859-67.

5. Cleveland JC Jr, Naftel DC, Reece TB, Murray M, Antaki J, Pagani FD, et al. Survival after biventricular assists device implantation: an analysis of the Interagency Registry for Mechanically Assisted Circulatory Support database. J Heart Lung Transplant. 2011;30:862-9.

\title{
Left ventricular vegetations: A rare manifestation of Libman-Sacks endocarditis
}

\author{
Naritomo Nishioka, MD, Naoto Morimoto, MD, PhD, Masato Yoshida, MD, PhD, and \\ Nobuhiko Mukohara, MD, PhD, Himeji-city, Japan
}

\footnotetext{
From the Department of Cardiovascular surgery, Hyogo Brain and Heart Center at Himeji, Himeji-city, Japan.

Disclosures: Authors have nothing to disclose with regard to commercial support.

Received for publication Oct 31, 2012; accepted for publication Nov 9, 2012; available ahead of print Dec 10, 2012

Address for reprints: Naritomo Nishioka, MD, Cardiovascular Surgery, Hyogo Brain and Heart Center at Himeji, 520 Saisho-kou, Himeji-city, Hyogo 670-0981, Japan (E-mail: naritomo.n@nifty.com).

J Thorac Cardiovasc Surg 2013;145:e26-8

$0022-5223 / \$ 36.00$

Copyright (C) 2013 by The American Association for Thoracic Surgery

http://dx.doi.org/10.1016/j.jtcvs.2012.11.034
}

Libman-Sacks endocarditis, first described by Libman and Sacks ${ }^{1}$ in 1924, is the pathognomonic valvular lesion of systemic lupus erythematosus or antiphospholipid antibody syndrome that may develop on the endocardial surface of the heart. These lesions have a propensity toward formation on the left valves, particularly the ventricular surface of the mitral valve. We report the case of a 26 -year-old woman without a history of cardiac disease who was seen for an atypical form of Libman-Sacks endocarditis. The disease progressed in an 


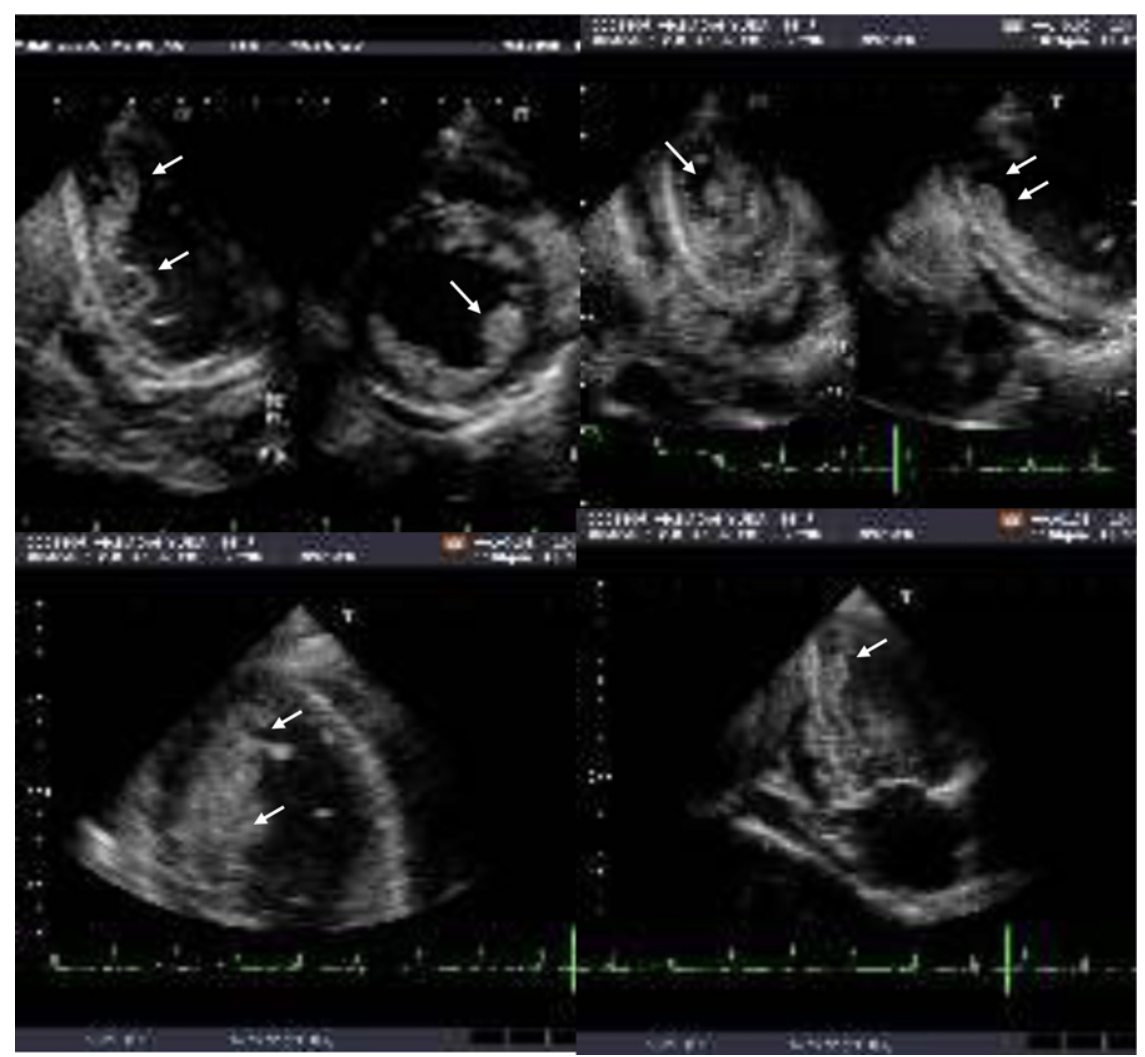

FIGURE 1. Echocardiography showed vegetations confined to the left ventricle.

unusually aggressive manner, with large vegetation formation in the left ventricular cavity. The cardiac valves functioned normally and were not affected by the disease.

\section{CLINICAL SUMMARY}

A 26-year-old woman was seen with multiple intracavitary left ventricular masses and congestive heart failure. One month previously, she had been seen with hematuria, low-grade fever, and development of renal failure and dyspnea on exertion.

After the patient's admission, fever, anuria, and hypotension were noted, in conjunction with increases in the serum levels of creatinine $(2.7 \mathrm{mg} / \mathrm{dL})$, creatine kinase (7012 IU/L), total bilirubin $(2.8 \mathrm{~g} / \mathrm{dL})$, aspartate aminotransferase (3359 IU/L), alanine aminotransferase (973 $\mathrm{IU} / \mathrm{L})$, and C-reactive protein $(7.0 \mathrm{mg} / \mathrm{dL})$ and a prolongation of prothrombin time (international normalized ratio of 2.75). Transthoracic echocardiography showed a left ventricular ejection fraction of $20 \%$ with diffuse hypokinesia and normal valves. Multiple mobile isoechoic mass lesions ranging from 2 to $5 \mathrm{~cm}$ were noted at the apex of the left ventricle (Figure 1). Inotropic support, continuous hemofiltration, and systemic anticoagulation with heparin were initiated in response to the suspicion of acute myocarditis complicated by left ventricular thrombus. Results of repeated blood cultures were negative, and there was no evidence of infective endocarditis. Emergency surgery for left ventricular thrombus was considered necessary to prevent thromboembolism.

At operation, the left ventricle was inspected through an aortotomy and lateral left atriotomy. Gray, fragile, solid masses were attached to the papillary muscles and left ventricular endocardium (Figure 2, $A$ and $B$ ). The aortic, mitral, and tricuspid valves were not affected. The masses were completely removed, and biopsy of the myocardium was performed.

Pathologic examination revealed that the masses were vegetations composed of organized thrombus, fibrin, and proliferation of monocytes, compatible with a diagnosis of Libman-Sacks endocarditis (Figure 2, $C$ and $D$ ). The specimen of the myocardium was indicative of myocarditis with perivascular and interstitial invasion of monocytes.

The patient's blood test results were positive for antinuclear, anti-double-strand DNA, and anti-cardiolipin $\beta 2$ glycoprotein antibodies. These findings confirmed the diagnosis of Libman-Sacks endocarditis and myocarditis associated with systemic lupus erythematosus and antiphospholipid antibody syndrome.

At 1 week after the operation, the patient began steroid pulse therapy (methylprednisolone at $1 \mathrm{~g} /$ day). After 3 months of steroid therapy, her ejection fraction was improved to $50 \%$ 


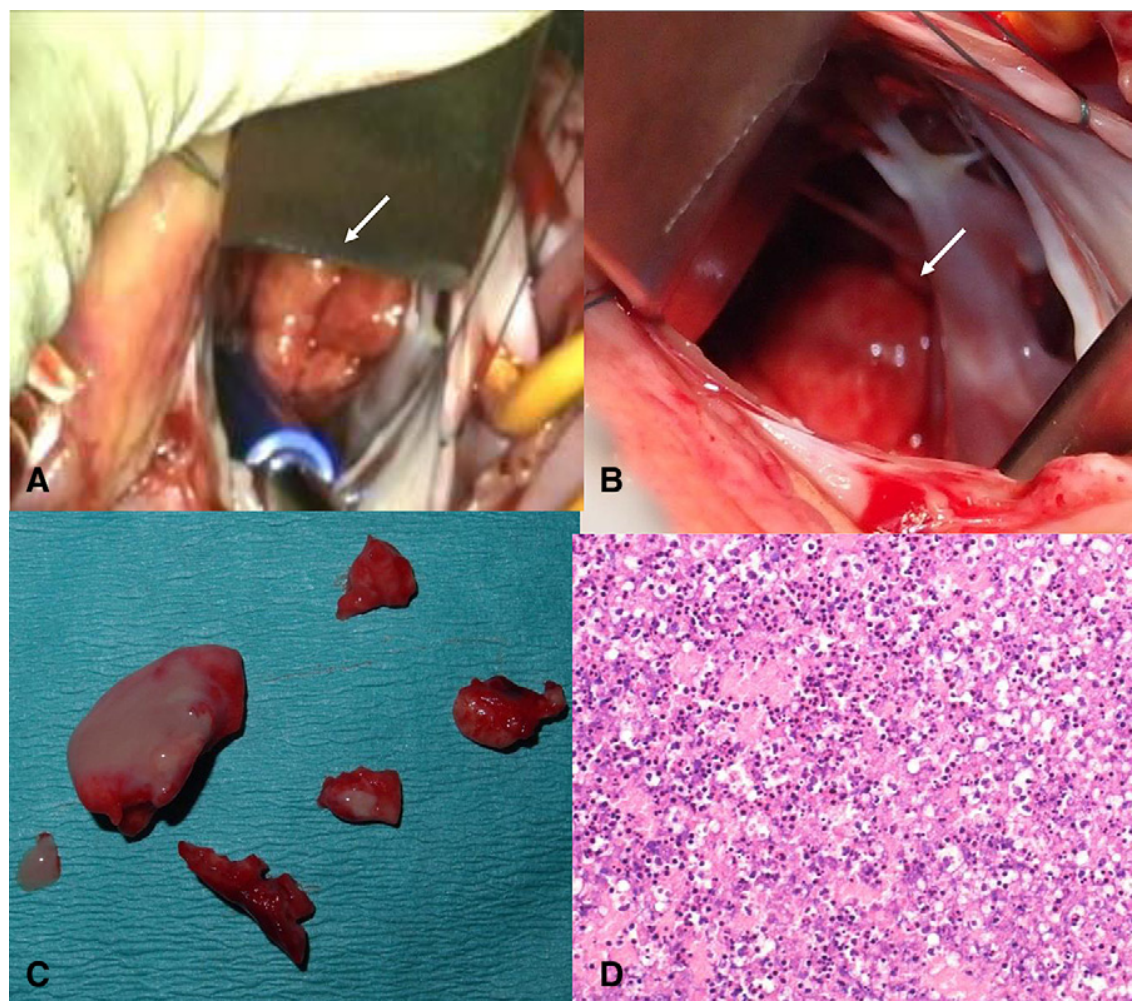

FIGURE 2. A and B, Intraoperative finding of vegetations (arrows) confined to the left ventricle. C, Gross specimen of resected vegetations. D, Pathologic finding of organized thrombus, fibrin, and proliferation of monocytes.

and her New York Heart Association functional class was improved to class I.

\section{DISCUSSION}

Myocarditis, characterized by perivascular and interstitial invasion by lymphocytes and often associated with congestive heart failure, is found in fewer than $10 \%$ of patients with systemic lupus erythematosus. ${ }^{2}$ In Libman-Sacks endocarditis, the vegetations may appear as pea sized (3-4 $\mathrm{mm}$ ), flat or slightly raised, granular, gray or pinkish projections, densely adherent to the endocardium and occurring most frequently at the valve rings and commissures, spreading over both valve surfaces, and even onto the atrial and ventricular mural endocardium, chordae tendineae, and papillary muscles. Libman-Sacks vegetations are microscopically characterized by fibrin deposits of various stages of fibroblastic organization and neovascularization and by variable extents of inflammation with mononuclear cell infiltration. Vegetations are typically sessile, wartlike, and small, varying from pinhead size to 3 to $4 \mathrm{~mm}$, although infrequently they grow to $10 \mathrm{~mm}$ or even larger through the formation of massive thrombotic lesions. ${ }^{3}$ Antiphospholipid antibodies are thought to promote thrombus formation on the endothelium of valves already compromised by immune complex deposition, leading to further valvular damage and inflammation. ${ }^{4}$ Ventricular vegetations in Libman-Sacks endocarditis are quite rare. The mechanism of their formation is unclear; however, endothelial damage or impaired left ventricular function may be a cause.

Most patients respond to high-dose corticosteroid therapy, although some require the addition of the immunosuppressive agents. In our case, myocarditis responded to high-dose corticosteroid therapy. Therapy with corticosteroids has been said to be associated with smaller and fewer vegetations and to act in secondary prevention of systemic embolism, but there is no evidence for this contention. Fox and coworkers ${ }^{5}$ reported cases of systemic embolism (brain, kidney, and spleen) from 10-mm Libman-Sacks mitral valve vegetations during the administration of high-dose prednisone. Indication for resection might include vegetations that are larger than $10 \mathrm{~mm}$ or are mobile. Although our patient responded to the steroid therapy and recovered cardiac function, continuous follow-up is mandatory.

\section{References}

1. Libman E, Sacks B. A hitherto undescribed form of valvular and mural endocarditis. Arch Intern Med. 1924;33:701-37.

2. Bulkley BH, Roberts WC. The heart in systemic lupus erythematosus and the changes induced in it by corticosteroid therapy: a study of 36 necropsy patients. Am J Med. 1975;58:243-64.

3. Doherty NE, Siegel RJ. Cardiovascular manifestations of systemic lupus erythematosus. Am Heart J. 1985;110:1257-65.

4. Bouma W, Kinkenberg TJ, van der Horst IC, et al. Mitral valve surgery for mitral regurgitation caused by Libman-Sacks endocarditis: a report of four cases and a systematic review of the literature. J Cardiothorac Surg. 2010;5:13.

5. Fox IS, Spence AM, Wheelis RF, Healey LA. Cerebral embolism in Libman-Sacks endocarditis. Neurology. 1980;30:487-91. 